Article

\title{
Lipid Oxidation Inhibition Capacity of 11 Plant Materials and Extracts Evaluated in Highly Oxidised Cooked Meatballs
}

\author{
Stina C. M. Burri ${ }^{1}, * \mathbb{C}$, Kajsa Granheimer ${ }^{1}$, Marine Rémy ${ }^{1}$, Anders Ekholm ${ }^{2}$, Åsa Håkansson ${ }^{1}$, \\ Kimmo Rumpunen ${ }^{2}$ and Eva Tornberg ${ }^{1}$ \\ 1 Department of Food Technology Engineering and Nutrition, Lund University, Naturvetarvägen 12, \\ 22362 Lund, Sweden; kajsagranheimer@hotmail.com (K.G.); marine.remy@agrosupdijon.fr (M.R.); \\ asa.hakansson@food.lth.se (Å.H.); eva.tornberg@food.lth.se (E.T.) \\ 2 Department of Plant Breeding, Swedish University of Agricultural Sciences, Fjälkestadsvägen 459, \\ 29194 Kristianstad, Sweden; anders.ekholm@slu.se (A.E.); kimmo.rumpunen@slu.se (K.R.) \\ * Correspondence: stina.burri@food.lth.se; Tel.: +46-462229808
}

Received: 7 August 2019; Accepted: 9 September 2019; Published: 12 September 2019

\begin{abstract}
The underlying mechanism(s) behind the potential carcinogenicity of processed meat is a popular research subject of which the lipid oxidation is a common suspect. Different formulations and cooking parameters of a processed meat product were evaluated for their capacity to induce lipid oxidation. Meatballs made of beef or pork, containing different concentrations of fat (10 or

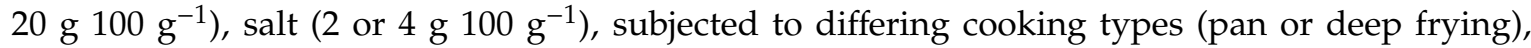
and storage times $(1,7$, and 14 days), were evaluated using thiobarbituric reactive substances (TBARS). The deep-fried meatball type most susceptible to oxidation was used as the model meat product for testing the lipid oxidation inhibiting capacity of 11 plant materials and extracts, in two concentrations (100 and $200 \mathrm{mg} \mathrm{kg}^{-1}$ gallic acid equivalent (GAE)), measured after 14 days of storage using TBARS. Summer savory lyophilized powder was the most efficient plant material, lowering lipid oxidation to $13.8 \%$ and $21.8 \%$ at the 200 and $100 \mathrm{mg} \mathrm{kg}^{-1}$ concentration, respectively, followed by a sea buckthorn leaf extract, lowering lipid oxidation to $22.9 \%$ at $100 \mathrm{mg} \mathrm{kg}^{-1}$, compared to the meatball without added antioxidants. The lipid oxidation was thus successfully reduced using these natural antioxidants.
\end{abstract}

Keywords: natural antioxidant; phenol; malondialdehyde; processed meat; Folin-Ciocalteu

\section{Introduction}

Since the International Agency for Research on Cancer (IARC) released their monograph stating that consumption of red and processed meats are linked to colorectal cancer (CRC) in 2015, research regarding this topic has increased, particularly since the mechanisms leading to these links remain partly unknown [1]. The most commonly proposed factors underlying the link between consumption of red/processed meat and CRC have been attributed to the following, partly overlapping, mechanisms: (I) An increase in oxidative or N-nitrosation load leading to lipid oxidation and DNA adducts in the intestinal epithelium, respectively; (II) stimulation of proliferation of the epithelium by heme or other food metabolites acting either directly or following conversion, e.g., heterocyclic amines (HCAs) and polycyclic aromatic hydrocarbons (PAHs) through high-temperature cooking; and (III) pro-malignant processes triggered by a higher inflammatory response, e.g., by a process where $\mathrm{N}$-glycolylneuraminic acid (Neu5Gc) is involved in developing xenosialitis, an inflammatory syndrome inducing cancer formation and progression $[2,3]$.

Processed meat refers to products typically made of red meat that have undergone curing, salting, or smoking, often containing high amounts of fatty tissues together with endogenous phospholipids [4]. 
These factors, together with high-temperature cooking, make them susceptible to oxidative reactions, which may contribute to health hazards [5]. The meatball dish, a minced meat product, is one of the Swedish trademarks in traditional cuisine. The world's largest furniture retailer, IKEA, claims they sell more than one billion meatballs per year [6]. Meatballs are industrially deep-fried, while usually pan-fried when homemade, and are typically made of pork and/or beef meat (fat content ranging

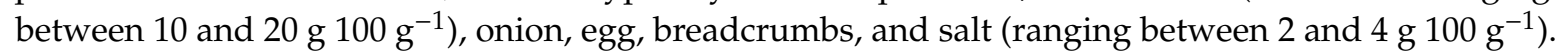
Meatballs were chosen as the study material due to the large market and the fact that the formulation and cooking process covers most of the main components of processed meat products in general.

The addition of antioxidants to meat, meat products, and meat model systems has been widely studied for oxidation preventing purposes [7]. Synthetic antioxidants, such as butylated hydroxytoluene (BHT), butylated hydroxyanisole (BHA), propyl gallate (PG), and tertiary butylhydroquinone (TBHQ), are commonly used in the food industry for oxidation-inhibiting purposes but are decreasing in use due to their suspected genotoxicity $[5,7]$. Hence, there is an increased demand of natural antioxidants, which could prevent the oxidation process of different meat products, potentially decreasing the negative health effects of processed meat products, as well as prolonging the shelf-life and promoting sustainability. For an evaluation of the lipid oxidation-inhibiting capacity of antioxidants in meat and meat products, the thiobarbituric reactive substances (TBARS) assay is frequently used [8-10]. Moreover, to obtain reliable results, it is important that the meat model used is appropriate for the product and supplements tested.

The aim of the present study was (I) to develop a relevant oxidized processed meatball model to study the effects of supplemented antioxidants, and (II) investigate lipid oxidation in meatballs without and with a range of plant materials and extracts at different concentrations.

\section{Materials and Methods}

\subsection{Plant Materials and Extracts}

Eleven plant materials and extracts were collected from Denmark, Estonia, Finland, Latvia, and Sweden (Table 1), i.e., from partners of the EU-project "Sustainable plant ingredients for healthier meat products-proof of concepts". Finnish phenol-rich extracts were prepared using pressurized hot water extraction (PHWE). Samples were obtained using a Dionex ASE 350 accelerated solvent extractor (Thermo Fischer Scientific Inc., Waltham, MA, USA). Extraction temperatures were $110^{\circ} \mathrm{C}$ and $120^{\circ} \mathrm{C}$ for sea buckthorn (Hippophae rhamnoides L.) leaves and bilberry leaves (Vaccinium myrtillus L.), respectively. The static extraction time was $1 \mathrm{~min}$ for both samples. After PHWE, the extracts were filtered and lyophilized. Estonian phenol-rich extracts were prepared using a pilot-scale solid-liquid

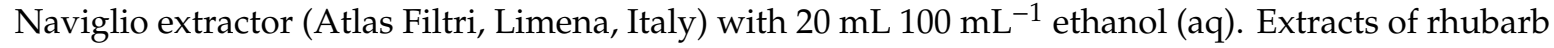
root (Rheum rhabarbarum L.) and black currant (Ribes nigrum L.) leaves were concentrated to half their volume and were lyophilized to a powder. The ethanol of the Swedish extracts (Table 1) was evaporated before they were diluted to the wanted concentrations. The summer savory (Satureja hortensis L.) powder was added non-extracted to the meat batter with the same amount of tap water as the extracts. The extracts were dissolved in MilliQ water prior to dilution in tap water and addition to the meat batter. All samples were analyzed for their total phenols content using Folin-Ciocalteu reagent [11]. 
Table 1. Samples of antioxidant plant materials and extraction methods used.

\begin{tabular}{|c|c|c|c|c|c|c|c|}
\hline Plant Material & Latin Name & Cultivar & Country & Extraction Solution & Abbreviation & Extraction Method & GAE $\mathrm{mg} \mathrm{mL}^{-1}$ Extract \\
\hline $\begin{array}{l}\text { Lyophilized Sea } \\
\text { buckthorn leaves }\end{array}$ & Hippophae rhamnoides L. & $\begin{array}{l}\text { 'Botnia } \\
\text { Guldklimp' }\end{array}$ & Finland & Pressurized hot water & SBTPHWE & Section 2.1 & 7.0 \\
\hline $\begin{array}{c}\text { Lyophilized } \\
\text { Bilberry leaves }\end{array}$ & Vaccinium myrtillus L. & Native stands & Finland & Pressurized hot water & BBPHWE & Section 2.1 & 11.6 \\
\hline $\begin{array}{c}\text { Sea buckthorn } \\
\text { leaves and sprouts }\end{array}$ & Hippophae rhamnoides L. & $\begin{array}{c}\text { Mix of } \\
\text { 'Botaničeskaja } \\
\text { Lubitel,skaja' and } \\
\text { 'Prozračnaja' }\end{array}$ & Latvia & 80\% Ethanol & SBT80 & Gornas et al. [12] & 13.2 \\
\hline $\begin{array}{c}\text { Sea buckthorn } \\
\text { leaves and sprouts }\end{array}$ & Hippophae rhamnoides L. & $\begin{array}{c}\text { Mix of } \\
\text { 'Botaničeskaja } \\
\text { Lubitelskaja' and } \\
\text { 'Prozračnaja' }\end{array}$ & Latvia & $\mathrm{H}_{2} \mathrm{O}$ & $\mathrm{SBTH}_{2} \mathrm{O}$ & $\begin{array}{c}\text { Modified from Gornas } \\
\text { et al. [12] }\end{array}$ & 9.2 \\
\hline $\begin{array}{c}\text { Summer savory } \\
\text { leaves }\end{array}$ & Satureja hortensis L. & $\begin{array}{l}\text { Seed origin: Hild } \\
\text { Samen }\end{array}$ & Denmark & Non-extracted & SS & Non-extracted & 12.0 \\
\hline $\begin{array}{c}\text { Sea buckthorn } \\
\text { leaves }\end{array}$ & Hippophae rhamnoides L. & 'Finskaja' & Sweden & $50 \%$ ethanol & SBT & Burri et al. [11] & 8.8 \\
\hline $\begin{array}{c}\text { Olive } \\
\text { Polyphenols-Phenoliv }\end{array}$ & Olea europaea L. & Phenoliv ${ }^{\mathrm{TM}}$ & Sweden & $50 \%$ ethanol & OS & Burri et al. [11] & 3.8 \\
\hline Onion skin & Allium cepa $\mathrm{L}$. & 'Donna' & Sweden & $50 \%$ ethanol & OPP & Burri et al. [11] & 3.0 \\
\hline Beetroot leaves & Beta vulgaris subsp. vulgaris & 'Action' & Sweden & $50 \%$ ethanol & $\mathrm{BR}$ & Burri et al. [11] & 1.0 \\
\hline $\begin{array}{l}\text { Lyophilized } \\
\text { rhubarb root }\end{array}$ & Rheum rhabarbarum $\mathrm{L}$. & 'Victoria' & Estonia & $20 \%$ ethanol & LRR & Section 2.1 & 18.1 \\
\hline $\begin{array}{l}\text { Lyophilized black } \\
\text { currant leaves }\end{array}$ & Ribes nigrum $\mathrm{L}$. & 'Pamjat Vavilova' & Estonia & $20 \%$ ethanol & LBC & Section 2.1 & 10.1 \\
\hline
\end{tabular}




\subsection{Chemicals}

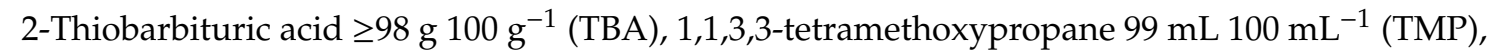

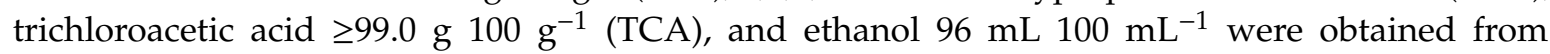
Sigma-Aldrich Inc., St. Louis, MO, USA. Hydrochloric acid $\left(40 \mathrm{mM} \mathrm{L}^{-1}\right)$ and $85 \mathrm{~mL} 100 \mathrm{~mL}^{-1}$ ortho-phosphoric acid $\left(\mathrm{H}_{3} \mathrm{PO}_{4}\right)$ were obtained from Merck KGaA, Darmstadt, Germany.

\subsection{Preliminary Trial for Meatball Model Selection}

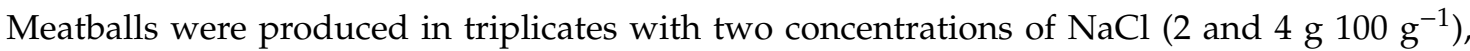

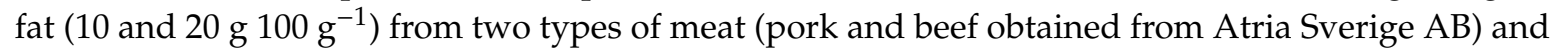
were either pan-fried or deep-fried, and stored for 1, 7, and 14 days (Figure 1). Lean meat from pork

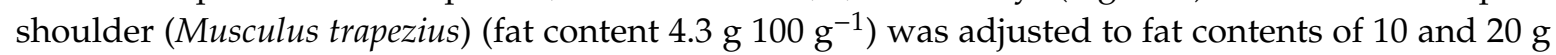
$100 \mathrm{~g}^{-1}$, respectively, during mincing using pork belly (M. external abdominal oblique) (fat content $28.2 \mathrm{~g}$

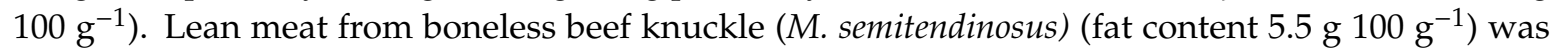
adjusted to the same fat contents using a mixture of cuts from beef chuck (M. deltoideus) and clod ( $M$.

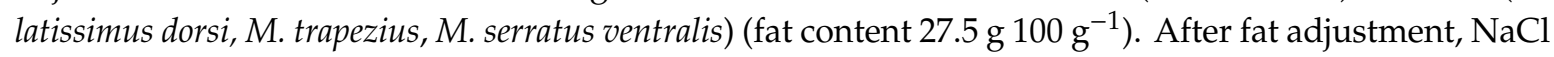
was added and blended to the mince before vacuum packing and freezing at $-18{ }^{\circ} \mathrm{C}$ until trials begun. The mince was thawed in a refrigerator $\left(4^{\circ} \mathrm{C}\right)$ overnight before meatballs were manufactured for the trial. Meatballs were either pan-fried or deep-fried in randomized order in refined rapeseed oil (Zeta,

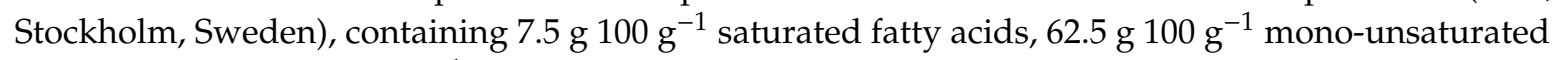

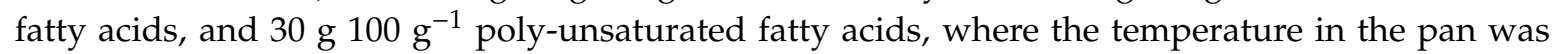
kept stable at $175^{\circ} \mathrm{C} \pm 1{ }^{\circ} \mathrm{C}$ controlled by a laser thermometer (IR-termometer Basetech IRT-350, Plano, Texas, USA) and the deep-frying temperature was kept stable at $160{ }^{\circ} \mathrm{C} \pm 0.5^{\circ} \mathrm{C}$. When the meatballs had reached a $72{ }^{\circ} \mathrm{C}$ inner temperature, they were removed from heating and rested on paper towels until room temperature was reached. The meatballs were then stored in a refrigerator $\left(4^{\circ} \mathrm{C}\right)$ in sealed polyethylene bags for 1,7 , and 14 days before the level of lipid oxidation was measured using thiobarbituric reactive substances (TBARS).

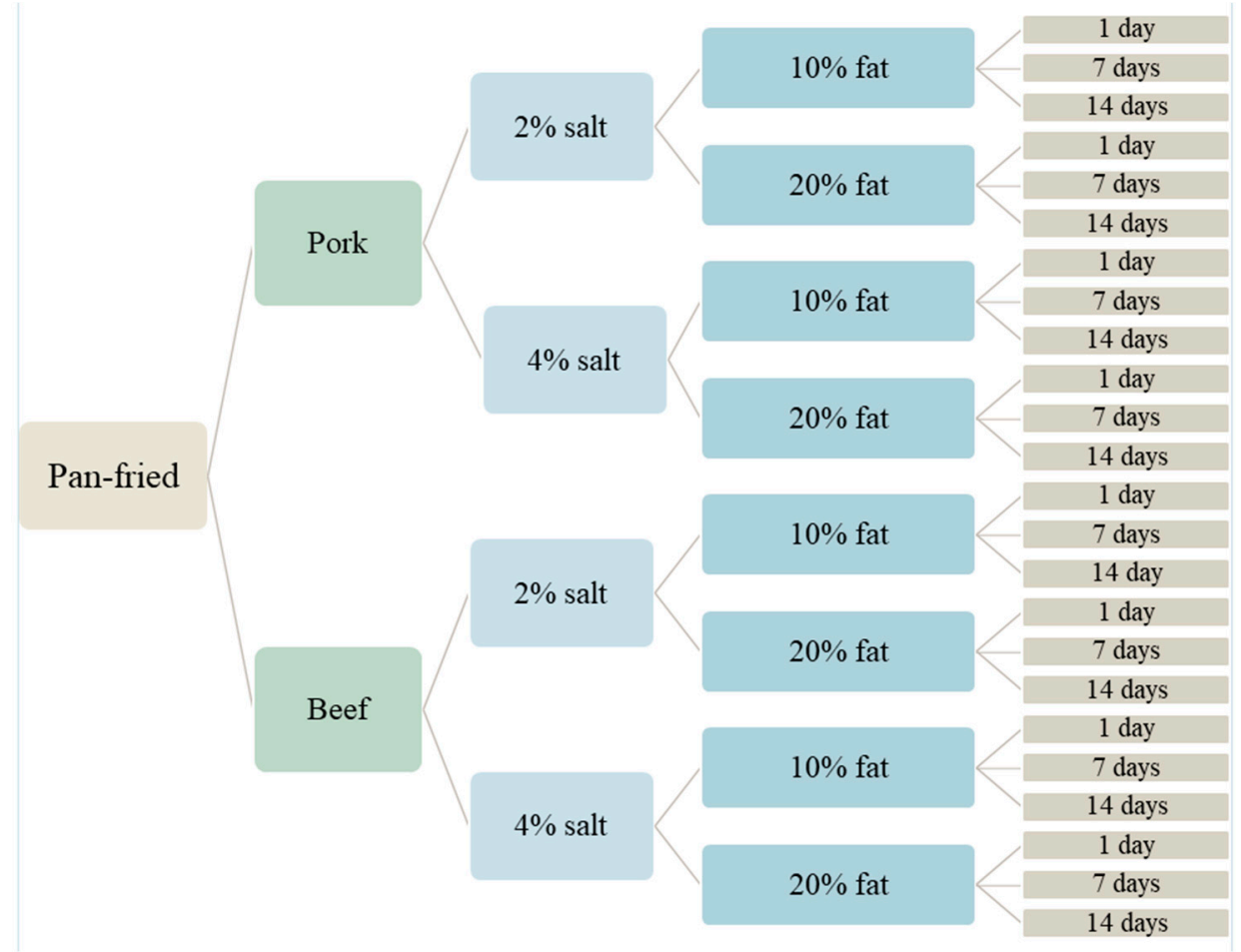

Figure 1. Scheme of the pan-fried meatball study set up as modified by Granheimer [13]. The same set up was used for the deep-fried meatball study. 


\subsection{Test of Antioxidants in Most Oxidized Pork Meatball}

The 11 antioxidant powders and extracts were added in 100 and $200 \mathrm{mg} \mathrm{kg}^{-1}$ of gallic acid equivalents (GAE), respectively, based on their total phenols content (Table 1) to the most oxidized

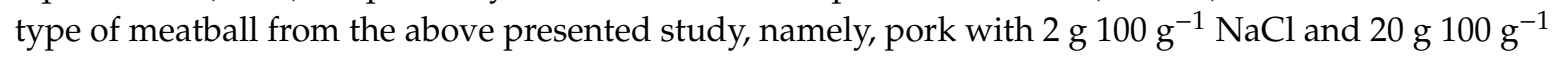
fat (weight by weight, which was deep-fried. In order to incorporate the antioxidants into the meat batters, $90 \mathrm{~g}$ of mince was mixed by hand with $9 \mathrm{~mL}$ of antioxidant solution until all fluid had been absorbed by the mince. Meatballs were hand-rolled and weighed in triplicates to a standardized weight of $16.5 \mathrm{~g} \pm 0.1 \mathrm{~g}$ before they were deep-fried as mentioned above at $160{ }^{\circ} \mathrm{C}$ until the inner temperature reached $72{ }^{\circ} \mathrm{C}$. The meatballs were then let to rest on paper towels until room temperature was reached. After 14 days in the refrigerator $\left(4^{\circ} \mathrm{C}\right)$, the level of lipid oxidation was measured using thiobarbituric reactive substances (TBARS).

\subsection{Thiobarbituric Reactive Substances (TBARS)}

The lipid oxidation was measured in triplicates for each meatball using TBARS based on the method of Buege and Aust [14], where the prepared TBA reagent consisted of $15 \mathrm{~g} 100 \mathrm{~mL}^{-1} \mathrm{TCA}$ and

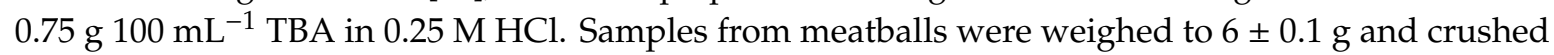
by mortar and pestle prior to being added to a 50-mL falcon tube containing $22.5 \mathrm{~mL}$ Milli-Q $\mathrm{H}_{2} \mathrm{O}$ together with $1.5 \mathrm{~mL}$ of $10 \mathrm{~g} 100 \mathrm{~mL}^{-1} \mathrm{TCA}$ solution. The samples were then vortexed for $60 \mathrm{~s}$ prior to heating at $40^{\circ} \mathrm{C}$ for $5 \mathrm{~min}$ to precipitate proteins, before $2 \mathrm{~mL} 96 \mathrm{~mL} 100 \mathrm{~mL}^{-1}$ ethanol was added to solubilize fats. The mixtures were then filtered through a filter paper (Munktell, grade $1 \mathrm{~F}$ ) to obtain a clear filtrate for TBARS analysis. In total, $2.5 \mathrm{~mL}$ of the TBA reagent was added to $0.5 \mathrm{~mL}$ of the filtrates, which were then heated to $90^{\circ} \mathrm{C}$ for $10 \mathrm{~min}$ before being cooled in tap water to end the reaction. All samples were centrifuged at $3600 \mathrm{~g}$ for 20 min (Allegra ${ }^{\circledR}$ X-15R, Beckman Coulter, Brea, CA, USA) before the absorbance of the supernatants was measured at $534 \mathrm{~nm}$ and $600 \mathrm{~nm}$, respectively (Varian Cary ${ }^{\circledR} 50$ UV-Vis Spectrophotometer, Agilent, Santa Clara, CA, USA). If the coefficient of variation (cv\%) between the sample replicates exceeded 10\%, the analyses were re-run. Results are reported as $\mu \mathrm{M}$ malondialdehyde (MDA) $\mathrm{g}^{-1}$ meatball for meatball parameter evaluations, and as a percentage oxidation of the blank sample (without added antioxidants) for antioxidant evaluation.

\subsection{Statistical Analyses}

Statistical analyses were carried out using SPSS Statistics 25.0 (IBM Corp. Released 2017. IBM SPSS Statistics for Windows, Version 25.0. Armonk, NY, USA) and R for Windows GUI front-end version 3.5.3 (R version 3.5.2 (2018-12-20) - “Eggshell Igloo" Copyright (C) 2018 The R Foundation for Statistical Computing Platform: x86_64-w64-mingw32/x64 (64-bit). Box-Cox transformations were used to achieve normal distribution of data. A univariate general linear model (GLM) was performed on logarithmic values of oxidation data in both the preliminary trial and antioxidant study in order to ensure normal distribution of samples (skewness and kurtosis with maximum values of \pm 1.96 [15]). In the preliminary trial, meat type, salt content, fat content, cooking type, and storage time were all fixed factors tested in a full-factorial GLM model on the dependent variable TBAR ( $\mu \mathrm{M}$ MDA g ${ }^{-1}$ meatball). In the antioxidant study, species and concentrations of antioxidants were fixed factors in the full-factorial model of the dependent variable percent lipid oxidation of meatballs compared to meatballs without antioxidants. In both trials, meatball samples were made in triplicates of which TBARS was measured in 3 technical replicates; statistical analyses were conducted on an average of the results of the meatball triplicates. Post-hoc tests were performed using the Scheffe method. A Pearson correlation analysis was conducted using SPSS on previous antioxidant activity data for the samples included in this study together with the lipid oxidation inhibiting capacity to study if, and if so, which antioxidant mode of action gave rise to the lipid oxidation inhibiting capacity. 


\section{Results}

\subsection{Preliminary Trial for Meatball Model Selection}

Lipid oxidation levels of meatballs differing in composition, cooking method, and time of storage are presented in Figure 2. Statistical results indicate that meat type, storage time, cooking type, and salt content all had significant effects on the lipid oxidation $(p<0.001)$ as did the fat content $(p<0.01)$. Nearly all interactions had significant effects on lipid oxidation $(p<0.05)$ except for interactions between: Salt $\times$ cooking, meat $\times$ salt $\times$ storage, meat $\times$ salt $\times$ fat $\times$ cooking, and meat $\times$ salt $\times$ fat $\times$ storage (Table A1). However, the partial Eta squared $\left(\eta^{2}\right)$ showed the effect sizes of most interactions were minor. The factors affecting lipid oxidation the most were meat type and storage time $(p<0.001)$ (Table A1), where pork oxidized more than beef, and where oxidation increased with longer storage times for both meat types, as is shown in the interaction between meat type and storage time (Figure 3a). There was an interaction between meat type and fat content (Figure 3b), where beef with $20 \mathrm{~g} 100 \mathrm{~g}^{-1}$

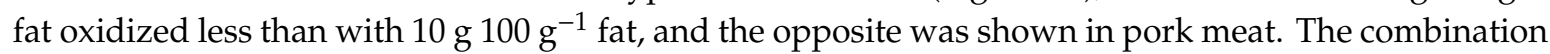

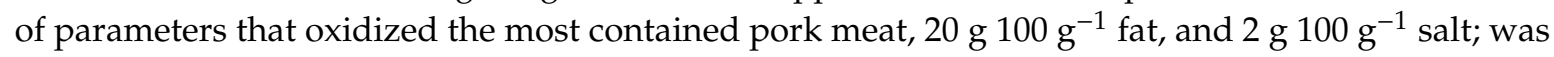
deep-fried; and was stored for 14 days (Figure 2) (Table A2).

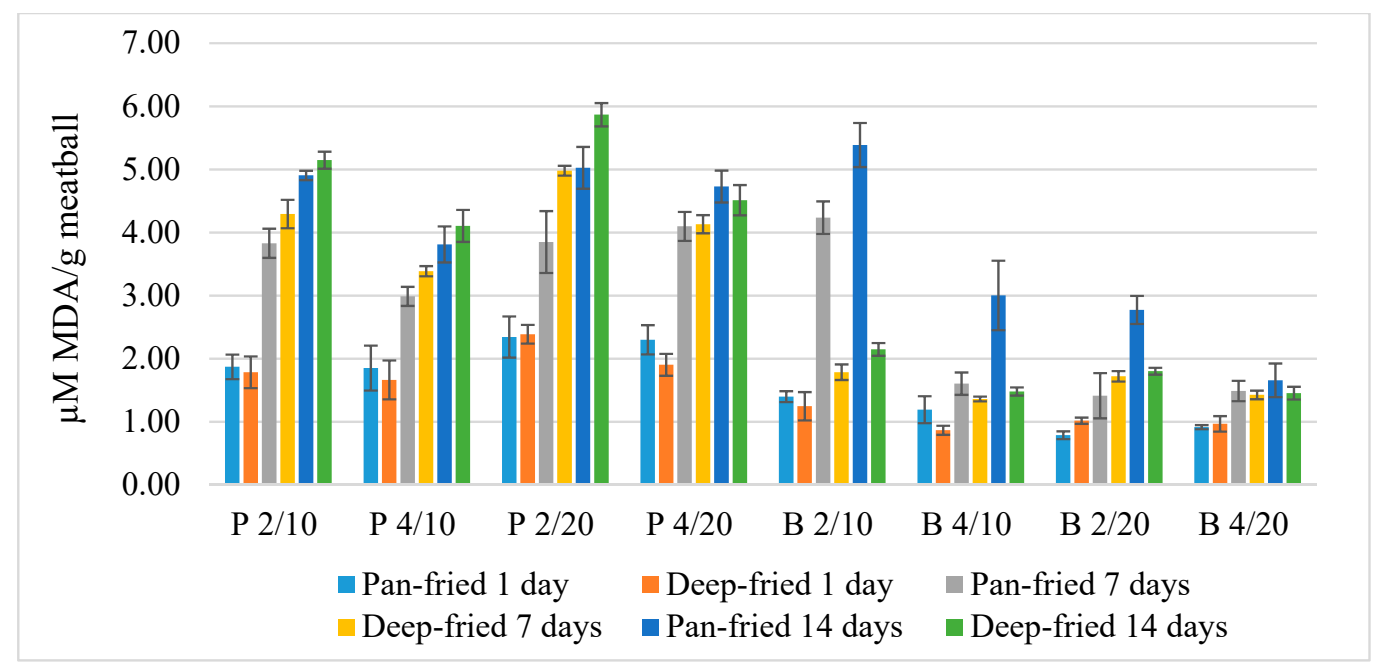

Figure 2. Lipid oxidation in model meatballs with differing parameters shown in $\mu \mathrm{M}$ malondialdehyde (MDA) $\mathrm{g}^{-1}$ meatball, where $\mathrm{P}=$ pork and $\mathrm{B}=$ beef meat. The numbers 2 and 4 correspond to the salt content in $\%$ and the numbers 10 and 20 correspond to the fat content in $\%$. The standard deviation is shown by the error bars $(n=3)$.

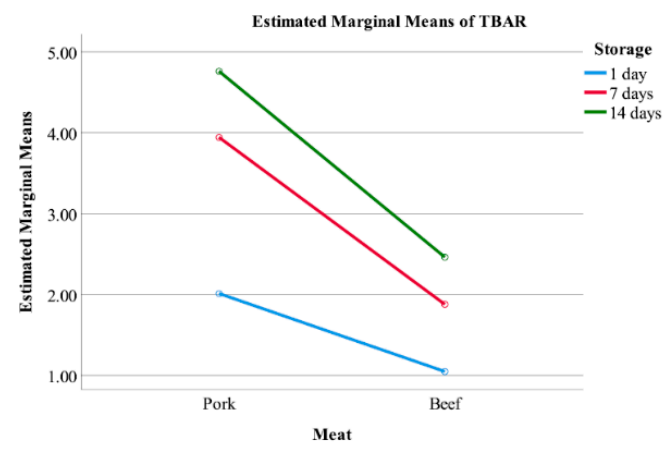

(a)

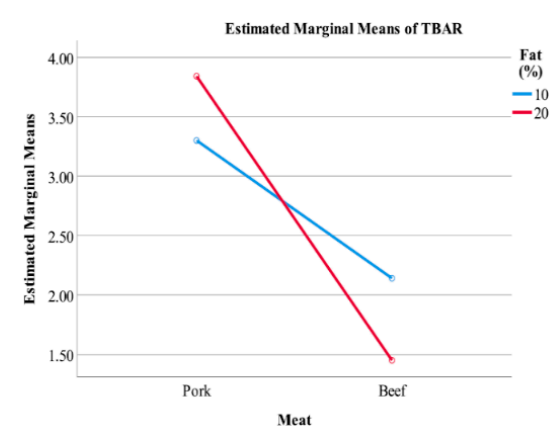

(b)

Figure 3. Main effect plots (estimated marginal means) of TBARS ( $\mu \mathrm{M}$ malondialdehyde $\mathrm{g}^{-1}$ meatball) of (a) the interaction between meat type and storage times and (b) the interaction between meat type and fat contents (\%). 


\subsection{Inclusion of Antioxidants in Most Oxidized Meatball}

All meatball samples were evaluated for their TBAR substances (malondialdehyde (MDA) $\mu \mathrm{M}$ $\mathrm{g}^{-1}$ ) in triplicates after 14 days of storage where the results were calculated as a percentage of oxidation compared to samples without added antioxidants ( $\mu \mathrm{M} \mathrm{MDA} \mathrm{g}{ }^{-1}$ meatball with plant material $/ \mu \mathrm{M}$ MDA g $^{-1}$ meatball without antioxidant) * 100) (Figure 4). Statistical results indicate that antioxidant species, concentrations, and the interaction of both significantly affected the level of lipid oxidation compared to the meatball without added antioxidants $(p<0.001)$ (Figure 4$)$ of which the antioxidant species was shown to have the largest effect size on the level of lipid oxidation (Table A3). The summer savory powder (Satureja hortensis L., SS) at $200 \mathrm{mg} \mathrm{kg}^{-1}$ and $100 \mathrm{mg} \mathrm{kg}^{-1}$, water extracted sea buckthorn (Hippophae rhamnoides L., SBTH2O) at $100 \mathrm{mg} \mathrm{kg}^{-1}$, and olive polyphenols (Olea europaea L., OPP) at $200 \mathrm{mg} \mathrm{kg}^{-1}$ were the most efficient antioxidants, lowering lipid oxidation to $13.8 \%, 21.8 \%, 22.9 \%$, and $26.1 \%$, respectively (Table A4), compared to the meatball with no added antioxidants. There were no significant correlations (Pearson) between the total phenols content (GAE mg mL ${ }^{-1}$ ) and the lipid oxidation inhibition capacity of the antioxidants (Table A5).

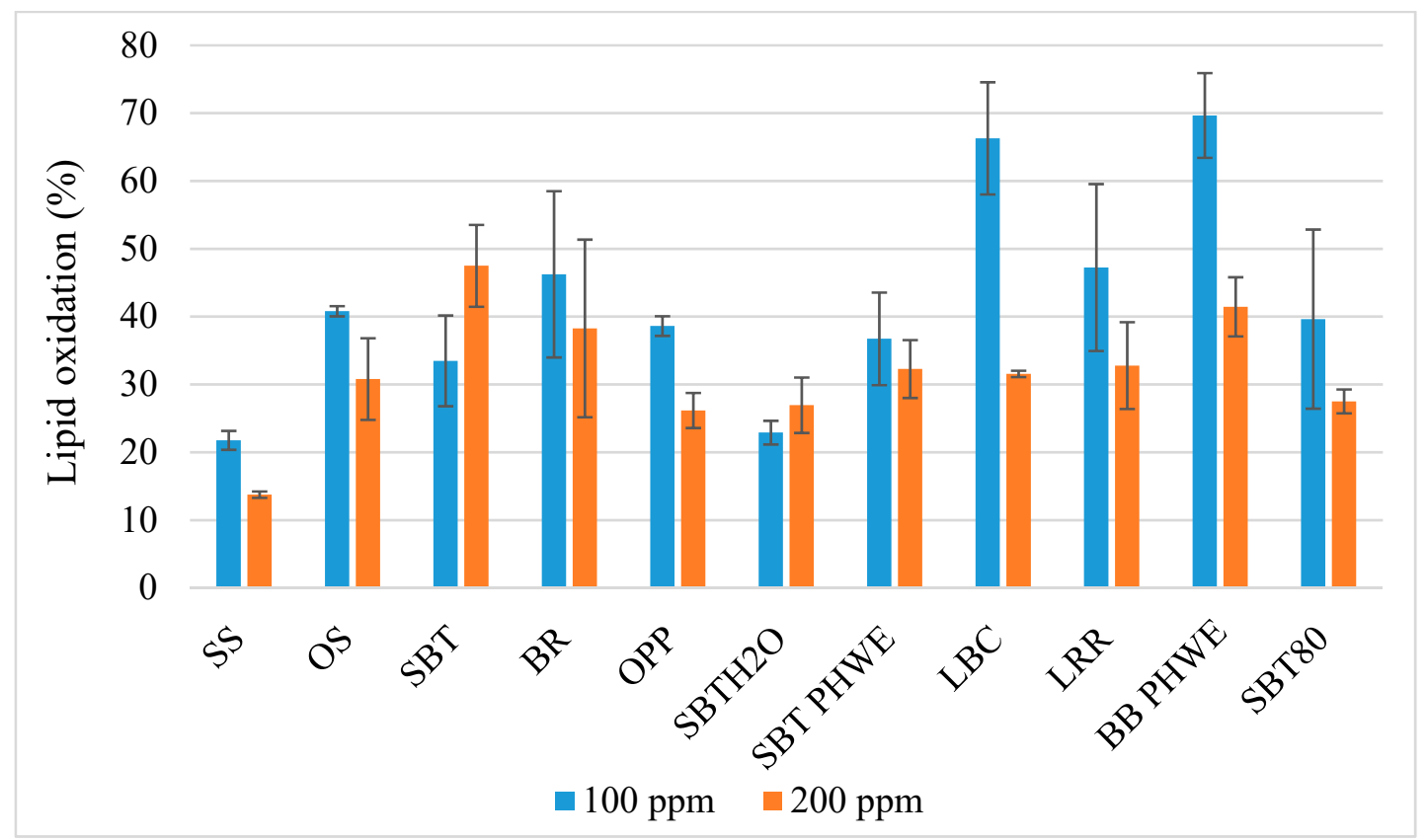

Figure 4. Lipid oxidation in the meatball type most prone to oxidize (pork with $2 \% \mathrm{NaCl}, 20 \% \mathrm{fat}(\mathrm{w} / \mathrm{w})$, deep-fried), with different antioxidants shown as a percentage of oxidation compared to the meatball without added antioxidants at two concentrations. SS = Summer Savory, OS = Onion skin, SBT = Sea buckthorn leaves, $\mathrm{BR}=$ Beetroot leaves, $\mathrm{OPP}=$ Olive polyphenols, $\mathrm{SBTH} 2 \mathrm{O}=$ water extracted sea buckthorn leaves and sprouts, SBT PHWE = Sea buckthorn leaves and sprouts-pressurized hot water extraction, $\mathrm{LBC}=$ Lyophilized black currant leaves, $\mathrm{LRR}=$ Lyophilized rhubarb root, $\mathrm{BB}$ PHWE $=$ Bilberry leaves-pressurized hot water extraction, and SBT80 = ethanol $(80 \%)$ extracted sea buckthorn leaves and sprouts. The standard deviation is shown by the error bars $(n=3)$.

\section{Discussion}

This study was divided into two parts, where the aim of the first part was to select a meatball model prone to oxidize. The aim of the second part of this work was to include and test various types of natural antioxidants for lipid oxidation inhibiting purposes. Both parts of the study will be discussed separately hereunder. 


\subsection{Preliminary Trial for Meatball Model Selection}

We found that meat type was the most important factor affecting lipid oxidation (Table A1) where the pork meatballs overall were significantly $(p<0.001)$ more prone to oxidize than those of beef meat (Figure 3). This was not according to our expectations since pork meat contains less myoglobin $\left(2 \mathrm{mg} \mathrm{g}^{-1}\right)$ than beef meat $\left(8 \mathrm{mg} \mathrm{g}^{-1}\right)$ [16], and since the heme-iron content in meat is commonly hypothesized to be one of the significant substances in red and processed meat inducing carcinogenesis due to its involvement in mutagenic nitroso-compounds (NOCs) and the production of reactive oxygen species (ROS), producing lipid oxidation secondary products, such as malondialdehyde (MDA) $[3,17,18]$. However, a plausible explanation for the obtained results of the meatballs made of beef or pork meat could be differences in the levels of polyunsaturated fatty acids (PUFA) frequently involved in lipid oxidation. Pork meat has considerably higher amounts of linoleic acid (18:2) in

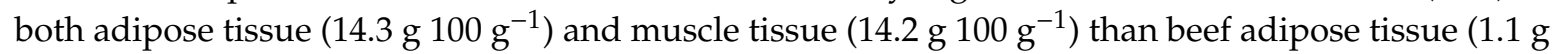

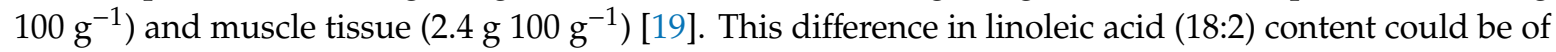
importance, since the oxidation in linoleic acid occurs 10 times faster than in oleic acid (18:1), and 20 to 30 times faster than linolenic acid (18:3) [17].

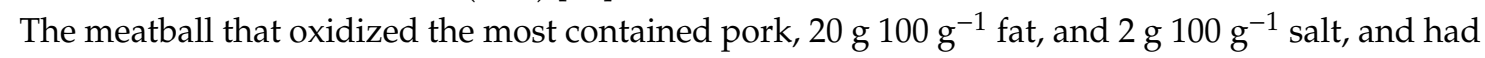
been deep-fried and stored for 14 days (Figure 2). This meatball type was then chosen for further analysis, although it did not statistically differ from other meatballs (Table A2), since the aim remained to find the meatball type with the most oxidizing combinations of parameters. Interestingly, the beef

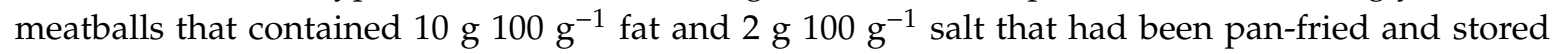
for one and 14 days oxidized more than the other combinations of beef meatballs (Figure 2), which could be an explanation for the antagonistic interaction between fat content and meat type (Figure $3 b$ ). Initially, we hypothesized that the higher the fat and salt contents in the meatballs, the higher the level of lipid oxidation, but this was not shown to be the case in our study. Salt $(\mathrm{NaCl})$ is generally known to be a pro-oxidant in meat and meat products [5]; however, salt contents over $3 \mathrm{~g} 100 \mathrm{~g}^{-1}$ have shown little to no pro-oxidant effect [17], which is in accordance with the findings in the present study (Figure 3).

Although we found significant effects of cooking types on the level of lipid oxidation (Table A1), both deep-frying and pan-frying are considered to belong to the dry heat cooking category [20]. Hence, the heat transfer could be considered to be equal between the cooking types in matters of changes in physiochemical properties. When meatballs were analyzed for fat loss during pan-frying, Granheimer [13] found that the beef meatballs had higher fat loss than those of pork. However, in our

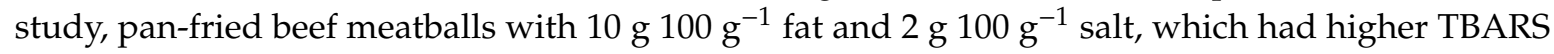
levels (Figure 3), instead gained fat. In the same study, beef meatballs were shown to gain more fat during deep-frying than pork meatballs, in which fat was lost [13]. Haak et al. [21] found that the fatty acid composition of pan-fried meats became similar to that of the culinary fat due to its fat uptake. This could then explain why the beef meatball oxidized more than the others since rapeseed oil contains

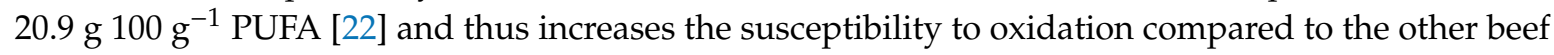
meatballs. That all meatballs oxidized more over time $(p<0.001)$ (Figure 3$)$ was expected due to the chain reaction nature of the lipid oxidation reaction.

\subsection{Test of Antioxidants in the Most Oxidized Pork Meatball}

Synthetic antioxidants have typically been included into meat products to increase, e.g., shelf-life and nutritional value, and now the industry is demanding new natural sources of antioxidant ingredients [5]. Numerous trials and experiments have successfully been carried out in screening the lipid oxidation inhibiting capacity of extracts from plant materials in various meat products [7]. For instance, olive leaf extracts have previously shown to be a potent antioxidant in bovine and porcine muscle model systems [9], oregano and sage essential oils have significantly reduced levels of lipid oxidation [8], and summer savory has previously been shown to reduce lipid oxidation in pork meatballs significantly [23]. All samples tested in our study effectively inhibited lipid oxidation 
at both concentrations $(p<0.001)$ (Figure 4$)$, where the summer savory (SS) powder was the most efficient at both concentrations, and statistically differed from all other samples at $200 \mathrm{mg} \mathrm{kg} \mathrm{g}^{-1}$ (Table A4). The statistical results showed that antioxidant species, concentration, and the interaction of both had significant effects on lipid oxidation $(p<0.001)$, where species had the largest effect size (Table A5). Overall, samples inhibited lipid oxidation more efficiently at $200 \mathrm{mg} \mathrm{kg}^{-1}$ than at $100 \mathrm{mg}$ $\mathrm{kg}^{-1}$ (Figure 4) except for the sea buckthorn sample extracted with $50 \mathrm{~mL} 100 \mathrm{~mL}^{-1}$ ethanol (SBT), which was significantly more effective at $100 \mathrm{mg} \mathrm{kg}^{-1}$, and the sea buckthorn sample extracted with $\mathrm{H}_{2} \mathrm{O}$ (SBTH2O), which showed tendencies to be more efficient at $100 \mathrm{mg} \mathrm{kg}^{-1}$. Radenkovs et al. [24] previously attributed this phenomenon to the phenol composition of each antioxidant, where reaction speed predominantly depends on each phenol's chemical structure rather than its concentration. This explanation is further reinforced when interpreting the non-significant correlation analysis (Table A5) between the total phenols content and inhibition of lipid oxidation capacity. In further research, meatballs without and with antioxidants will be tested in vivo to evaluate potential changes in intestinal inflammatory reactions following a diet consisting of $20 \mathrm{~g} 100 \mathrm{~g}^{-1}$ of these meatballs.

\section{Conclusions}

The aim of the current study was to evaluate the lipid oxidation inhibiting capacity of natural antioxidants in a readily oxidized meat product. Various meatball properties were studied in order to find the combination that gave rise to the most lipid oxidation. The meatball most prone to oxidize

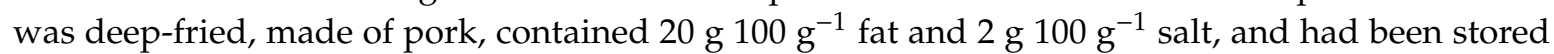
for 14 days. This meatball type was then manufactured without and with 11 different plant materials and extracts at two concentrations, $100 \mathrm{mg} \mathrm{kg}^{-1}$ and $200 \mathrm{mg} \mathrm{kg}^{-1} \mathrm{GAE}$, and was stored for 14 days. All samples inhibited lipid oxidation effectively in both tested concentrations, where the summer savory powder was the most efficient in both the $100 \mathrm{mg} \mathrm{kg}^{-1}$ and $200 \mathrm{mg} \mathrm{kg}^{-1}$ concentration, lowering lipid oxidation to $21.8 \%$ and $13.8 \%$, respectively, compared to meatballs with no added antioxidants. Thus, antioxidant rich plant materials and extracts could efficiently prevent lipid oxidation in processed meat products, such as meatballs.

Author Contributions: Conceptualization, E.T. and S.C.M.B.; methodology, E.T.; software, S.C.M.B.; validation, E.T., K.R. and A.E.; formal analysis, S.C.M.B. and K.R.; investigation, S.C.M.B., K.G., A.E. and M.R.; resources, K.R.; data curation, S.C.M.B.; writing-original draft preparation, S.C.M.B.; writing-review and editing, K.R., K.G., Å.H.; visualization, S.C.M.B.; supervision, K.R., Å.H.; project administration, K.R.; funding acquisition, K.R., Å.H., E.T.

Funding: This work was supported by the Swedish Research Council for Environment, Agricultural Sciences and Spatial Planning (Grant 222-2014-1923) within the ERA-NET SUSFOOD transnational cooperation programme (including Denmark, Estonia, Finland, Latvia and Sweden) for the project SUSMEATPRO, "Sustainable plant ingredients for healthier meat products-proof of concepts".

Acknowledgments: We thank Sofia Stüffe and Hans Mathiason at Atria Supply AB for their help in accomplishing this work and for their contribution of meat. We also thank Uko Bleive and Tõnu Püssa from the Estonian University of Life Sciences, Estonia, Martin Jensen from Aarhus University, Denmark, Jarkko Hellström, Sari Mäkinen, Risto Korpinen and Pirjo Mattila from the Natural Resources Institute, Finland, Vitalijs Radenkovs and Dalija Seglina from the Institute of Horticulture, Latvia, for their help in acquiring and extracting plant materials for this study.

Conflicts of Interest: The authors declare no conflict of interest. The funders had no role in the design of the study; in the collection, analyses, or interpretation of data; in the writing of the manuscript, or in the decision to publish the results. 


\section{Appendix A}

Table A1. General Linear model (GLM) table of the lipid oxidation affecting parameters on the variable TBAR, where $^{*}=p<0.05,{ }^{* *}=p<0.01$, and ${ }^{* *}=p<0.001$. Df $=$ Degrees of freedom. The parameters with the largest effect sizes are shown in bold.

\begin{tabular}{|c|c|c|c|c|c|c|c|}
\hline & Df & $\begin{array}{l}\text { Sum of } \\
\text { Squares }\end{array}$ & $\begin{array}{l}\text { Mean } \\
\text { Square }\end{array}$ & F Value & $p$ Value & $\operatorname{Pr}(>F)$ & $\begin{array}{c}\text { Partial Eta } \\
\text { Squared }\end{array}$ \\
\hline Meat & 1 & 18.12 & 18.12 & 2142.5 & $<0.001$ & $* * *$ & 0.957 \\
\hline Fat & 1 & 0.06 & 0.06 & 7.6 & 0.007 & $* *$ & 0.074 \\
\hline Cooking type & 1 & 0.40 & 0.40 & 47.5 & $<0.001$ & $* * *$ & 0.331 \\
\hline Meat $\times$ Fat & 1 & 1.98 & 1.98 & 234.2 & $<0.001$ & $* * *$ & 0.709 \\
\hline Salt $\times$ Fat & 1 & 0.36 & 0.36 & 42.4 & $<0.001$ & $* * *$ & 0.306 \\
\hline Meat $\times$ Cooking & 1 & 1.01 & 1.01 & 119.2 & $<0.001$ & $* * *$ & 0.554 \\
\hline Salt $\times$ Cooking & 1 & 0.01 & 0.01 & 0.7 & 0.405 & & 0.007 \\
\hline Fat $\times$ Cooking & 1 & 0.54 & 0.54 & 63.5 & $<0.001$ & $* * *$ & 0.398 \\
\hline Meat $\times$ Salt $\times$ Fat & 1 & 0.14 & 0.14 & 16.4 & 0.000 & $* * *$ & 0.146 \\
\hline Meat $\times$ Salt $\times$ Cooking & 1 & 0.27 & 0.27 & 31.6 & $<0.001$ & $* * *$ & 0.247 \\
\hline Meat $\times$ Fat $\times$ Cooking & 1 & 0.49 & 0.49 & 58.3 & $<0.001$ & $* * *$ & 0.378 \\
\hline Salt $\times$ Fat $\times$ Cooking & 1 & 0.25 & 0.25 & 29.5 & $<0.001$ & $* * *$ & 0.235 \\
\hline Meat $\times$ Salt $\times$ Storage & 2 & 0.04 & 0.02 & 2.4 & 0.095 & & 0.048 \\
\hline Meat $\times$ Fat $\times$ Storage & 2 & 0.08 & 0.04 & 5.0 & 0.009 & $* *$ & 0.094 \\
\hline Salt $\times$ Fat $\times$ Storage & 2 & 0.17 & 0.08 & 10.1 & 0.000 & $* * *$ & 0.173 \\
\hline Meat $\times$ Cooking $\times$ Storage & 2 & 0.75 & 0.37 & 44.2 & $<0.001$ & $* * *$ & 0.479 \\
\hline Salt $\times$ Cooking $\times$ Storage & 2 & 0.09 & 0.05 & 5.4 & 0.006 & $* *$ & 0.100 \\
\hline Fat $\times$ Cooking $\times$ Storage & 2 & 0.09 & 0.04 & 5.2 & 0.007 & $* *$ & 0.097 \\
\hline
\end{tabular}


Table A2. Combinations of parameters promoting lipid oxidation ranked from highest to lowest value, where DF = Deep-frying, PF = Pan-frying, CI = Confidence interval, and EMM = estimated marginal means. The standard error was 0.053 and the degrees of freedom were 96 for all samples. All samples were compared pairwise and were assigned one or more group letters to present their respective significant difference or lack thereof.

\begin{tabular}{|c|c|c|c|c|c|c|c|c|}
\hline Meat & Salt (\%) & Fat (\%) & $\begin{array}{c}\text { Cooking } \\
\text { Type }\end{array}$ & $\begin{array}{c}\text { Storage } \\
\text { Time } \\
\text { (Days) }\end{array}$ & $\begin{array}{l}\text { TBAR } \\
\text { EMM }\end{array}$ & $\begin{array}{l}\text { Lower } \\
\text { CI Limit }\end{array}$ & $\begin{array}{l}\text { Upper } \\
\text { CI Limit }\end{array}$ & Group \\
\hline Pork & 2 & 20 & DF & 14 & 2.819 & 2.714 & 2.925 & $\mathrm{a}$ \\
\hline Beef & 2 & 10 & $\mathrm{PF}$ & 14 & 2.681 & 2.576 & 2.787 & $\mathrm{ab}$ \\
\hline Pork & 2 & 10 & DF & 14 & 2.610 & 2.505 & 2.716 & $a b c$ \\
\hline Pork & 2 & 20 & $\mathrm{PF}$ & 14 & 2.574 & 2.468 & 2.679 & abcd \\
\hline Pork & 2 & 20 & DF & 7 & 2.560 & 2.455 & 2.666 & abcd \\
\hline Pork & 2 & 10 & $\mathrm{PF}$ & 14 & 2.539 & 2.433 & 2.644 & abcd \\
\hline Pork & 4 & 20 & $\mathrm{PF}$ & 14 & 2.485 & 2.379 & 2.590 & bcde \\
\hline Pork & 4 & 20 & DF & 14 & 2.417 & 2.311 & 2.522 & bcde \\
\hline Pork & 2 & 10 & DF & 7 & 2.347 & 2.242 & 2.453 & cdef \\
\hline Beef & 2 & 10 & PF & 7 & 2.330 & 2.224 & 2.435 & cdef \\
\hline Pork & 4 & 20 & DF & 7 & 2.296 & 2.191 & 2.402 & def \\
\hline Pork & 4 & 10 & DF & 14 & 2.286 & 2.180 & 2.391 & def \\
\hline Pork & 4 & 20 & $\mathrm{PF}$ & 7 & 2.284 & 2.178 & 2.389 & def \\
\hline Pork & 2 & 20 & $\mathrm{PF}$ & 7 & 2.199 & 2.094 & 2.305 & efg \\
\hline Pork & 2 & 10 & $\mathrm{PF}$ & 7 & 2.195 & 2.089 & 2.300 & efg \\
\hline Pork & 4 & 10 & PF & 14 & 2.188 & 2.083 & 2.294 & efg \\
\hline Pork & 4 & 10 & DF & 7 & 2.043 & 1.938 & 2.149 & fgh \\
\hline Beef & 4 & 10 & $\mathrm{PF}$ & 14 & 1.899 & 1.793 & 2.004 & ghi \\
\hline Pork & 4 & 10 & PF & 7 & 1.898 & 1.793 & 2.004 & ghi \\
\hline Beef & 2 & 20 & PF & 14 & 1.816 & 1.710 & 1.921 & hij \\
\hline Pork & 2 & 20 & DF & 1 & 1.664 & 1.559 & 1.769 & ijk \\
\hline Pork & 2 & 20 & $\mathrm{PF}$ & 1 & 1.645 & 1.540 & 1.750 & ijkl \\
\hline Pork & 4 & 20 & PF & 1 & 1.627 & 1.522 & 1.732 & ijkl \\
\hline Beef & 2 & 10 & DF & 14 & 1.565 & 1.459 & 1.670 & jklm \\
\hline Pork & 4 & 20 & DF & 1 & 1.458 & 1.353 & 1.563 & $\mathrm{klmn}$ \\
\hline Pork & 2 & 10 & $\mathrm{PF}$ & 1 & 1.442 & 1.336 & 1.547 & klmn \\
\hline Pork & 4 & 10 & PF & 1 & 1.430 & 1.324 & 1.535 & klmno \\
\hline Beef & 2 & 20 & DF & 14 & 1.412 & 1.306 & 1.517 & klmnop \\
\hline Beef & 2 & 10 & DF & 7 & 1.403 & 1.298 & 1.509 & klmnop \\
\hline Pork & 2 & 10 & DF & 1 & 1.402 & 1.296 & 1.507 & klmnop \\
\hline Beef & 2 & 20 & DF & 7 & 1.374 & 1.268 & 1.479 & klmnop \\
\hline Beef & 4 & 20 & PF & 14 & 1.342 & 1.237 & 1.448 & lmnop \\
\hline Pork & 4 & 10 & DF & 1 & 1.342 & 1.237 & 1.447 & lmnop \\
\hline Beef & 4 & 10 & $\mathrm{PF}$ & 7 & 1.317 & 1.212 & 1.423 & mnopq \\
\hline Beef & 4 & 20 & $\mathrm{PF}$ & 7 & 1.260 & 1.155 & 1.366 & mnopqr \\
\hline Beef & 4 & 10 & DF & 14 & 1.257 & 1.152 & 1.363 & mnopqrs \\
\hline Beef & 4 & 20 & DF & 14 & 1.244 & 1.139 & 1.350 & nopqrs \\
\hline Beef & 4 & 20 & DF & 7 & 1.230 & 1.125 & 1.336 & nopqrs \\
\hline Beef & 2 & 10 & $\mathrm{PF}$ & 1 & 1.217 & 1.112 & 1.322 & nopqrst \\
\hline Beef & 2 & 20 & $\mathrm{PF}$ & 7 & 1.217 & 1.111 & 1.322 & nopqrst \\
\hline Beef & 4 & 10 & DF & 7 & 1.198 & 1.093 & 1.304 & nopqrst \\
\hline Beef & 2 & 10 & DF & 1 & 1.133 & 1.027 & 1.238 & opqrstu \\
\hline Beef & 4 & 10 & $\mathrm{PF}$ & 1 & 1.104 & 0.999 & 1.209 & pqrstu \\
\hline Beef & 2 & 20 & DF & 1 & 1.011 & 0.905 & 1.116 & qrstu \\
\hline Beef & 4 & 20 & DF & 1 & 0.978 & 0.873 & 1.084 & rstu \\
\hline Beef & 4 & 20 & PF & 1 & 0.949 & 0.844 & 1.055 & stu \\
\hline Beef & 4 & 10 & DF & 1 & 0.919 & 0.814 & 1.025 & $\mathrm{tu}$ \\
\hline Beef & 2 & 20 & PF & 1 & 0.868 & 0.762 & 0.973 & $\mathrm{u}$ \\
\hline
\end{tabular}


Table A3. GLM table of the lipid oxidation affecting parameters on the variable TBAR of meat products with different supplemented antioxidants, where ${ }^{* * *}=p<0.001$, and Df $=$ Degrees of freedom. The parameter with the largest effect size is shown in bold.

\begin{tabular}{cccccccc}
\hline & Df & $\begin{array}{c}\text { Sum of } \\
\text { Squares }\end{array}$ & $\begin{array}{c}\text { Mean } \\
\text { Square }\end{array}$ & $\boldsymbol{F}$ Value & $p$ Value & Pr $(>\boldsymbol{F})$ & $\begin{array}{c}\text { Partial Eta } \\
\text { Squared }\end{array}$ \\
\hline Species & 10 & $\mathbf{0 . 0 2 4}$ & 0.002 & 37.6 & $<0.001$ & $* * *$ & 0.895 \\
Concentration & 1 & 0.005 & 0.005 & 72.7 & $<0.001$ & $* * *$ & 0.623 \\
Species $\times$ Concentration & 10 & 0.005 & 0.001 & 8.1 & $<0.001$ & $* * *$ & 0.647 \\
Residuals & 44 & 0.003 & 0.000 & & & & \\
\hline
\end{tabular}

Table A4. Combinations of species and concentrations of antioxidants resulting in the lowest lipid oxidation level, where SS = Summer Savory, OS = Onion skin, SBT = Sea buckthorn leaves, BR = Beetroot leaves, $\mathrm{OPP}=$ Olive polyphenols, $\mathrm{SBTH} 2 \mathrm{O}=$ water extracted sea buckthorn leaves and sprouts, SBT PHWE = Sea buckthorn leaves and sprouts-pressurized hot water extraction, LBC = Lyophilized black currant leaves, LRR = Lyophilized rhubarb root, BB PHWE = Bilberry leaves - pressurized hot water extraction, SBT80 = ethanol $(80 \%)$ extracted sea buckthorn leaves and sprouts, CI = Confidence interval, and EMM = estimated marginal means. The standard error was 0.005 and the degrees of freedom were 44 for all samples. Note that the higher the value, the lower the level of oxidation due to a boxcox-transformation of the dependent variable with ^ -0.7 . All samples were compared pairwise and were assigned one or more group letters to present their respective significant difference or lack thereof.

\begin{tabular}{|c|c|c|c|c|c|}
\hline Concentration (ppm) & Species & TBAR EMM & Lower CI Limit & Upper CI Limit & Group \\
\hline 200 & SS & 0.157 & 0.148 & 0.166 & a \\
\hline 100 & SS & 0.113 & 0.104 & 0.123 & $b$ \\
\hline 100 & SBTH2O & 0.110 & 0.100 & 0.119 & bc \\
\hline 200 & OPP & 0.100 & 0.091 & 0.109 & bcd \\
\hline 200 & SBTH2O & 0.098 & 0.089 & 0.108 & bcd \\
\hline 200 & SBT80 & 0.096 & 0.087 & 0.105 & bcde \\
\hline 200 & OS & 0.090 & 0.081 & 0.099 & bcdef \\
\hline 200 & $\mathrm{BR}$ & 0.088 & 0.079 & 0.097 & cdef \\
\hline 200 & LBC & 0.087 & 0.078 & 0.096 & cdef \\
\hline 200 & SBT PHWE & 0.086 & 0.077 & 0.096 & cdef \\
\hline 200 & LRR & 0.086 & 0.077 & 0.095 & cdef \\
\hline 100 & SBT & 0.085 & 0.075 & 0.094 & cdefg \\
\hline 100 & SBT PHWE & 0.080 & 0.070 & 0.089 & defg \\
\hline 100 & SBT80 & 0.077 & 0.068 & 0.087 & defg \\
\hline 100 & OPP & 0.076 & 0.066 & 0.085 & defgh \\
\hline 100 & OS & 0.073 & 0.063 & 0.082 & efghi \\
\hline 200 & BB PHWE & 0.072 & 0.063 & 0.082 & efghi \\
\hline 100 & LRR & 0.067 & 0.058 & 0.076 & fghi \\
\hline 200 & SBT & 0.066 & 0.056 & 0.075 & fghi \\
\hline 100 & $\mathrm{BR}$ & 0.060 & 0.051 & 0.069 & ghi \\
\hline 100 & LBC & 0.052 & 0.043 & 0.061 & hi \\
\hline 100 & BB PHWE & 0.050 & 0.041 & 0.059 & $\mathrm{i}$ \\
\hline
\end{tabular}

Table A5. Pearson correlation between total phenols content (GAE $\mathrm{mg} \mathrm{mL}^{-1}$ ) and TBARS values at the $100 \mathrm{mg} \mathrm{kg}^{-1}$ and $200 \mathrm{mg} \mathrm{kg}^{-1}$ concentration where $n=11$.

\begin{tabular}{|c|c|c|c|c|c|}
\hline & & Total Phenols & TBARS 100 & TBARS 200 & Species \\
\hline \multirow[t]{2}{*}{ Total phenols } & Correlation & 1 & 0.100 & -0.1333 & 0.543 \\
\hline & \multicolumn{2}{|c|}{$p$ value } & 0.768 & 0.695 & 0.084 \\
\hline \multirow{2}{*}{ TBARS 100} & Correlation & 0.100 & 1 & 0.482 & 0.566 \\
\hline & $p$ value & 0.768 & & 0.133 & 0.069 \\
\hline \multirow[t]{2}{*}{ TBARS 200} & Correlation & -0.133 & 0.482 & 1 & 0.204 \\
\hline & $p$ value & 0.696 & 0.133 & & 0.547 \\
\hline \multirow[t]{2}{*}{ Species } & Correlation & 0.543 & 0.566 & 0.204 & 1 \\
\hline & $p$ value & 0.084 & 0.069 & 0.547 & \\
\hline
\end{tabular}




\section{References}

1. International Agency for Research on Cancer (IARC). IARC Monographs Evaluate Consumption of Red Meat and Processed Meat; WHO: Lyon, France, 2015.

2. Hammerling, U.; Bergman Laurila, J.; Grafström, R.; Ilbäck, N.-G. Consumption of Red/Processed Meat and Colorectal Carcinoma: Possible Mechanisms Underlying the Significant Association. Crit. Rev. Food Sci. Nutr. 2016, 56, 20. [CrossRef] [PubMed]

3. Cascella, M.; Bimonte, S.; Barbieri, A.; Del Vecchio, V.; Caliendo, D.; Schiavone, V.; Fusco, R.; Granata, V.; Arra, C.; Cuomo, A. Dissecting the mechanisms and molecules underlying the potential carcinogenicity of red and processed meat in colorectal cancer (CRC): An overview on the current state of knowledge. Infect. Agent Cancer 2018, 13, 3. [CrossRef] [PubMed]

4. Domingo, J.L.; Nadal, M. Carcinogenicity of consumption of red meat and processed meat: A review of scientific news since the IARC decision. Food Chem. Toxicol. 2017, 105, 256-261. [CrossRef] [PubMed]

5. Jiang, J.; Xiong, Y.L. Natural antioxidants as food and feed additives to promote health benefits and quality of meat products: A review. Meat Sci. 2016, 120, 107-117. [CrossRef] [PubMed]

6. Israelsson, L. Ikeas köttbullar inte helt svenska-Kött från Irland. Expressen 2019.

7. Kumar, Y.; Yadav, D.N.; Ahmad, T.; Narsaiah, K. Recent trends in the use of natural antioxidants for meat and meat products. Compr. Rev. Food Sci. Food Saf. 2015, 14, 796-812. [CrossRef]

8. Fasseas, M.K.; Mountzouris, K.C.; Tarantilis, P.A.; Polissiou, M.; Zervas, G. Antioxidant activity in meat treated with oregano and sage essential oils. Food Chem. 2008, 106, 1188-1194. [CrossRef]

9. Hayes, J.E.; Stepanyan, V.; Allen, P.; O'Grady, M.N.; O'Brien, N.M.; Kerry, J.P. The effect of lutein, sesamol, ellagic acid and olive leaf extract on lipid oxidation and oxymyoglobin oxidation in bovine and porcine muscle model systems. Meat Sci. 2009, 83, 201-208. [CrossRef] [PubMed]

10. Lee, S.K.; Han, J.H.; Decker, E.A. Antioxidant activity of phosvitin in phosphatidylcholine liposomes and meat model systems. Food Chem. Toxicicol. 2002, 67, 37-41. [CrossRef]

11. Burri, C.M.S.; Ekholm, A.; Håkansson, Å.; Tornberg, E.; Rumpunen, K. Antioxidant capacity and major phenol compounds of horticultural plant materials not usually used. J. Funct. Foods 2017, 38, 119-127. [CrossRef] [PubMed]

12. Gornas, P.; Sne, E.; Siger, A.; Seglina, D. Sea buckthorn (Hippophae rhamnoides L.) leaves as valuable source of lipophilic antioxidants: The effect of harvest time, sex, drying and extraction methods. Ind. Crops Prod. 2014, 60, 1-7. [CrossRef]

13. Granheimer, K. Different Parameters Affecting Lipid Oxidation in Meatballs. Master's Thesis, Lund University, Lund, Sweden, 2017.

14. Buege, A.J.; Aust, S.D. Microsomal Lipid Peroxidation. Methods Enzym. 1978, 52, 302-310.

15. Kim, H.Y. Statistical notes for clinical researchers: Assessing normal distribution (2) using skewness and kurtosis. Restor. Dent. Endod. 2013, 38, 52-54. [CrossRef] [PubMed]

16. Hedrick, H.B.; Aberle, E.D.; Forrest, J.C.; Judge, M.D. Principles of Meat Science, 3rd ed.; Kendall Hunt: Dubuque, IA, USA, 2013.

17. Amaral, A.B.; da Silva, M.V.; Lannes, S.C.D.S. Lipid oxidation in meat: Mechanisms and protective factors-A review. Food Sci. Technol. 2018, 38, 15. [CrossRef]

18. Joosen, A.M.; Kuhnle, G.G.; Aspinall, S.M.; Barrow, T.M.; Lecommandeur, E.; Azqueta, A.; Collins, A.R.; Bingham, S.A. Effect of processed and red meat on endogenous nitrosation and DNA damage. Carcinogenesis 2009, 30, 1402-1407. [CrossRef] [PubMed]

19. Pereira, F.A.L.; Abreu, G.V.K. Lipid Peroxidation in Meat and Meat Products. In Lipid Peroxidation, Edited Volume; Catala, A., Mansour, M.A., Eds.; IntechOpen: London, UK, 2018.

20. Pearson, A.M.; Gillett, T.A. Processed Meats, 3rd ed.; Oregon State University: Corvallis, OR, USA, 2012.

21. Haak, L.; Sioen, I.; Raes, K.; Camp, J.; Smet, S. Effect of pan-frying in different culinary fats on the fatty acid profile of pork. Food Chem. 2007, 102, 857-864. [CrossRef]

22. Orsavova, J.; Misurcova, L.; Ambrozova, J.V.; Vicha, R.; Mlcek, J. Fatty Acids Composition of Vegetable Oils and Its Contribution to Dietary Energy Intake and Dependence of Cardiovascular Mortality on Dietary Intake of Fatty Acids. Int. J. Mol. Sci. 2015, 16, 12871-12890. [CrossRef] [PubMed] 
23. Lindberg-Madsen, H.; Andersen, L.; Christiansen, L.; Brockhoff, P.; Bertelsen, G. Antioxidative activity of summer savory (Satureja hortensis L.) and rosemary (Rosmarinus officinalis L.) in minced, cooked pork meat. Z. Lebensm. Unters. Forsch. 1996, 203, 333-338. [CrossRef]

24. Radenkovs, V.; Püssa, T.; Juhnevica-Radenkova, K.; Anton, D.; Seglina, D. Phytochemical characterization and antimicrobial evaluation of young leaf/shoot and press cake extracts from Hippophae rhamnoides L. Food Biosci. 2018, 24, 10. [CrossRef]

C 2019 by the authors. Licensee MDPI, Basel, Switzerland. This article is an open access article distributed under the terms and conditions of the Creative Commons Attribution (CC BY) license (http://creativecommons.org/licenses/by/4.0/). 